\title{
Planejamento na educação infantil: entre necessidades, saberes e práticas
}

\section{Planificación en la educación infantil: entre necesidades, conocimientos y prácticas}

Adriana Nicolaio

Graduação

Universidade Estadual de Ponta Grossa - UEPG

Ponta Grossa, Paraná - Brasil. adriielucas@hotmail.com

Marcela Pontarolo Gruvald

Graduação

Universidade Estadual de Ponta Grossa - UEPG

Ponta Grossa, Paraná - Brasil.

marcelapontarolo@hotmail.com

Daiana Camargo

Doutora em Ciências da Educação Universidade Estadual de Ponta Grossa - UEPG Ponta Grossa, Paraná - Brasil. camargo.daiana@hotmail.com

\begin{abstract}
Resumo: Partimos da realidade vivenciada durante o Estágio Curricular Supervisionado de Docência e das vivências enquanto professorasauxiliares e nos dedicamos a compreender qual a concepção das professoras sobre o planejamento. Buscamos fundamentos teóricos que nos auxiliaram a refletir sobre o planejamento, como os encontrados em Redin (2014) e Ostetto (2000; 2012). Os dados gerados foram obtidos por meio de questionários, categorizados e analisados com base no referencial teórico adotado. Apontamos algumas distorções entre a compreensão sobre o planejamento e o ato de planejar a prática pedagógica, o que aponta para a necessidade de formação constante e aprofundamento das discussões quanto ao que se faz e como se faz a prática pedagógica com a criança pequena.
\end{abstract}

Palavras chave: educação infantil; planejamento; prática pedagógica.

Resumen: Partimos de la realidad vivida durante la Pasantía Curricular Docente Supervisada y de las experiencias como profesores auxiliares, nos dedicamos a entender qué conciben los docentes sobre la planificación. Buscamos fundamentos teóricos que nos ayudaron a reflexionar sobre la planificación como Redin (2014) y Ostetto (2000; 2012). Los datos generados se obtuvieron a través de un cuestionario, categorizados y analizados en base al marco teórico adoptado. Señalamos algunas distorsiones entre la comprensión de la planificación y el acto de planificar la práctica pedagógica, lo que apunta a la necesidad de una constante formación y profundización de las discusiones sobre qué se hace y cómo se hace la práctica pedagógica con el niño pequeño.

Palabras-clave: Educación Infantil; planificación; práctica pedagógica.

Cite como

\section{(ABNT NBR 6023:2018)}

NICOLAIO, Adriana; GRUVALD, Marcela Pontarolo; CAMARGO, Daiana. Planejamento na educação infantil: entre necessidades, saberes e práticas. Dialogia, São Paulo, n. 39, p. 1-18, e20594, set./dez. 2021. Disponível em: https://doi.org/10.5585/39.2021.20594.

American Psychological Association (APA)

Nicolaio, A., Gruvald, M. P., \& Camargo, D. (2021, set./dez.) Planejamento na educação infantil: entre necessidades, saberes e práticas. Dialogia, São Paulo, 39, p. 1-18, e20738. https://doi.org/10.5585/39.2021.20594. 


\section{Sobre a pesquisa: indagações acerca do planejamento}

À medida que caminhamos para a conclusão do curso de Pedagogia, nos deparamos com diversas indagações e olhamos com maior atenção e cuidado para as particularidades da prática pedagógica em suas diferentes etapas da Educação Básica. A atuação como professoras ${ }^{1}$ de crianças pequenas durante o tempo de formação nos permitiu avistar as peculiaridades do cotidiano da Educação Infantil, indagando e refletindo sobre diferentes situações, práticas, modelos e ações desenvolvidas.

Ao adentrarmos outras instituições de Educação Infantil por ocasião da realização do Estágio de Docência, logo nas primeiras inserções para reconhecimento do espaço educativo e sua realidade, nos salta aos olhos a questão do planejamento. Fica evidente a existência de um registro, um planejamento físico, um documento, porém verificamos a organização do cotidiano e as práticas desenvolvidas sem conexão entre elas e destas com o plano escrito. Assim, nos inquietamos com a ausência de um fio condutor ou uma ação que demonstrasse preparo e intencionalidade.

Com vistas a identificar quais as compreensões acerca do planejar, a fim de organizarmos as propostas de estágio, as primeiras conversas com as professoras nos apresentam o entendimento do planejamento como algo burocrático, sem ênfase ao processo de construção (contexto, conhecimentos, saberes das crianças e seus interesses).

Assim, delineamos a pesquisa com a intenção de compreender qual a concepção das professoras sobre o planejamento, seu significado e sua importância na prática pedagógica. Partimos de uma pesquisa bibliográfica, demarcando as principais contribuições teóricas para pensarmos o planejamento (GAMA; FIGUEIREDO, 2009; SCARPATO, 2004) e o planejamento na Educação Infantil (REDIN, 2014; OSTETTO 2000; 2012). Na sequência, uma pesquisa de campo realizada com professores da Educação Infantil de instituições de Educação Infantil da rede pública e privada na cidade de XXXXXXXXX.

Os dados foram obtidos com a aplicação de um questionário ${ }^{2}$, e, com base nas respostas, foi possível fazermos algumas reflexões em relação ao planejamento a partir do entendimento e das experiências das professoras de crianças pequenas. Ressaltamos serem visíveis alguns descompassos no que diz respeito à articulação entre teoria e prática na execução (e entendimento) do planejamento, que se revelam no cumprimento rígido de conteúdos e rotinas sem a

\footnotetext{
1 O curso de Formação de Docentes de nível médio garante o direito da atuação como professora, embora a legislação (LDB 9394-96) apresente como preferencial a formação em nível superior.

2 O questionário foi estruturado com questões abertas e fechadas, em sua primeira parte indagando sobre a formação e o tempo de experiência dos profissionais, e em sua segunda parte organizamos questões abordando o conceito de planejamento, a realização do planejam ento no cotidiano educativo e a relação entre planejamento e prática pedagógica.
} 
problematização quanto às possibilidades da criança, do tempo e dos espaços para a organização das propostas desenvolvidas nas instituições educativas para a criança pequena.

\section{As práticas e o cotidiano da educação infantil}

Ao passo que tomamos como objetivo pensar o planejar no contexto da Educação Infantil, é preciso entendermos o que se fala e se pensa sobre prática pedagógica. Para Sacristán (1999, p. 73), “a prática educativa é o produto final a partir do qual os profissionais adquirem o conhecimento prático que eles poderão aperfeiçoar". O autor considera que o professor assume a função de guia reflexivo, iluminando as ações em sala de aula e interferindo significativamente na construção do conhecimento do aluno. Quando realiza essa tarefa, isso lhe proporciona reflexões sobre a prática pedagógica, pois se parte do pressuposto de que, ao assumir a atitude problematizadora da prática, modifica-se sendo modificado, gerando uma cultura objetiva da prática educativa (SACRISTÁN, 1999).

A prática educativa, especialmente a relacionada à Educação Infantil, deve oferecer, segundo Barbosa (2009), práticas e vivências conforme o que a criança pensa e sente. Segundo a autora:

[...] não bastam espaços, materiais e repertórios adequados, há a necessidade da presença de adultos sensíveis, atentos para transformar o ambiente institucional em um local onde predomina a ludicidade. É necessário que o profissional que atua diretamente com a criança pequena tenha conhecimento sobre a "cultura lúdica", um amplo repertório que possa ser oferecido às crianças nas diversas circunstâncias e, principalmente, compartilhe a alegria, a beleza e a ficção da brincadeira. (BARBOSA, 2009, p. 73-74).

Diante da necessidade de compreendermos o que se fez e o que se faz com a criança pequena na instituição educativa, Redin et al. (2014, p. 29) nos dizem que dinamizar o cotidiano de uma sala de aula com crianças passa pela desconstrução de prescrições encontradas tanto em manuais como em práticas reprodutivistas. Entretanto, as autoras destacam que as recomendações são bem-vindas, visto que ajudam o professor ou a atendente infantil a cumprir com seus objetivos, porém precisam de contextualização e reflexão.

Outra questão importante é que, ao pensarmos em linhas norteadoras de projetos e práticas pedagógicas para os pequenos, devemos entender "que o conhecimento é construído pela criança em um complexo indissociável de interações com o meio físico e social pela sua ação, construindo para si valores e regras e sendo assim sujeito de seu processo" (REDIN et al., 2014, p. 67). 
Assim, precisam ser oportunizadas propostas que permitam às crianças o conhecimento do próprio corpo e a exploração de objetos, no âmbito das sensações, percepções e movimentos, tendo por base um ambiente desafiador que estimule o atendimento às necessidades de afeto, sono, alimentação e higiene (REDIN et al., 2014). Estas necessidades de explorar, sentir e conhecer demarcam as especificidades da Educação Infantil.

\section{0 que há de diferente ao pensarmos o planejamento na educação infantil?}

Consideramos o planejamento como um instrumento norteador das ações pedagógicas, de grande importância tanto para a Educação Infantil como para as outras etapas educativas. No que diz respeito às peculiaridades da Educação Infantil, a construção e o desenvolvimento do planejamento são abordados em documento de caráter prescritivo, as Diretrizes Curriculares Nacionais para a Educação Infantil (BRASIL, 2009). Sobre as Diretrizes, recorremos ao Parecer CNE/CEB n. 20/2009, que apresenta o relatório sobre a proposta, com considerações de grande relevância para o entendimento do documento.

No parecer citado, a aprendizagem e o conhecimento no âmbito da Educação Infantil estão vinculados à intencionalidade, ao planejamento e ao acompanhamento. Quanto ao ato de planejar, são enfatizados elementos como atividades diversificadas, atenção à faixa etária e planejamento diversificado.

Entendemos, assim, que o planejamento das experiências educativas precisa contribuir para a formação de uma criança capaz de cuidar de si, do outro e do meio em que vive. O planejamento precisa acolher a diversidade, as situações, as realidades, os desafios do cotidiano, planejar com quem cuida e educa, educa e cuida. As DCNEIs (2009) enfatizam que educar cuidando remete à acolhida, segurança, às possibilidades do brincar, do criar, do expressar-se.

\footnotetext{
Educar de modo indissociável do cuidar é dar condições para as crianças explorarem o ambiente de diferentes maneiras (manipulando materiais da natureza ou objetos, observando, nomeando objetos, pessoas ou situações, fazendo perguntas etc.) e construírem sentidos pessoais e significados coletivos, à medida que vão se constituindo como sujeitos e se apropriando de um modo singular das formas culturais de agir, sentir e pensar. Isso requer do professor ter sensibilidade e delicadeza no trato de cada criança, e assegurar atenção especial conforme as necessidades que identifica nas crianças. (BRASIL, 2009, p. 10)
}

No cumprimento dessa exigência, o planejamento curricular deve assegurar condições para a organização do tempo cotidiano das instituições de Educação Infantil, de modo a equilibrar continuidade e inovação nas atividades, movimentação e concentração das crianças, momentos de segurança e momentos de desafio na participação em atividades, e articular seus ritmos individuais, 
vivências pessoais e experiências coletivas com crianças e adultos.

Outro aspecto importante ao pensar o planejamento é a estruturação de espaços que facilitem que as crianças interajam e construam sua cultura de pares e favoreçam o contato com a diversidade de produtos culturais (livros de literatura, brinquedos, objetos e outros materiais), valorização de manifestações artísticas e da criação com elementos da natureza. Neste sentido, Craidy e Kaercher (2001) e seus colaboradores apontam a importância da seleção dos materiais, dos recursos (livros, canções, imagens, etc.), da definição dos espaços e na sua forma de organização.

Com isso, há necessidade também de um olhar e de um cuidado ampliado, contemplando tanto os aspectos da infraestrutura e de formas de funcionamento da instituição que garantam ao espaço físico a adequada conservação, acessibilidade, estética, ventilação, insolação, luminosidade, acústica, higiene, segurança e dimensões em relação ao tamanho dos grupos e às propostas realizadas.

Os estudos realizados por Guerra e Asseker (2011) destacam que, ao construir uma proposta pedagógica, ela deve contemplar o educar, o brincar e o cuidar, o que significa planejar ações pedagógicas para que isso ocorra, tornando-se um dos aspectos importantes que norteiam o trabalho do professor em sala. Os resultados apresentados pelas autoras evidenciam que, mesmo entre os profissionais de uma única instituição de ensino, os planejamentos podem variar de professor para professor, dado que suas formações acadêmicas, suas experiências e a importância que atribuem ao planejamento diferenciam-se de uns para outros.

Guerra e Asseker (2011, p.3) afirmam:

[...] o mais importante para o educador é sensibilizar o olhar de forma receptiva e aberta aos seus alunos, buscando suas dificuldades e especificações subjetivas, para, dessa forma, colher informações que possam auxiliar na construção de atividades que busquem o avanço de cada aluno.

Ressaltamos, de tal modo, que o professor precisa organizar um planejamento pensado para a criança e com a criança, buscando adequar a necessidade de cada faixa etária, integrando o cuidar e o brincar como componentes do mesmo processo de desenvolvimento da criança, conhecer a criança e as suas necessidades. Cabe aqui as contribuições de Junqueira Filho (2005), ao abordar sobre a parte cheia e a parte vazia do planejamento, aquilo que conhecemos, sabemos, desejamos, e aquilo que chega no decorrer do cotidiano educativo, as necessidades e os desejos das crianças, seus conhecimentos, as situações vividas na comunidade. 
Ostetto (2012) ressalta ser preciso uma metodologia que não tenha somente objetivos, ou objetivos predefinidos, mas que contemple uma proposta muito mais ampla para enfrentar os limites existentes e seja repensada e reconstituída no cotidiano da criança: "buscar alternativas para superar esses limites só é possível, no entanto, partindo-se de princípios e referenciais teóricos consistentes, de uma prática intencional e de um inabalável e profundo compromisso com a criança" (OSTETTO, 2012, p. 48).

Nesse viés, o importante é ter um planejamento que inclua uma postura investigativa, mas sem burocratizar o processo, como, no caso analisado, formar para a cidadania, passando da teoria para a prática, na pesquisa e na construção do conhecimento, estando-se sempre atento às mudanças sociais, aos interesses dos grupos e ao sentido da aprendizagem para as crianças.

\section{Formas e especificidades do planejar na Educação Infantil: organizar, ouvir e rever}

É fundamental pensar a Educação Infantil como um direito garantido para as crianças de zero a 5 anos. Educação que implica formação, espaços físicos, equipe de apoio, organização pedagógica e envolvimento de muitas pessoas. A constituição da prática pedagógica com as crianças e para as crianças instiga ao traçar modos de fazer, testar, criar, registrar, entendendo o processo de planejar como fio condutor de descobertas, de possibilidades, de reflexão.

Ostetto (2012) considera que "planejar é essa atitude de traçar, projetar, programar, elaborar um roteiro para empreender uma viagem de conhecimento, de interação, de experiências múltiplas e significativas para com o grupo de crianças.” (OSTETTO, 2012, p. 1). Esse planejamento deve buscar intencionalidade em todo esse processo de ensino-aprendizagem.

No planejamento destinado à Educação Infantil, é primordial que o professor valorize as situações vividas pelas crianças, a fim de que se resolvam conflitos, superem preconceitos e se conheçam. Para isso, é preciso que haja diferentes maneiras de se planejar essas atividades.

Contudo, existem categorias de planejamento para que os professores possam executar seus planejamentos de maneira sempre adequada e correspondendo às necessidades das crianças, conforme a faixa etária. Ostetto (2011) descreve os planejamentos como os projetos baseados em datas comemorativas, temas de interesses, aspectos do desenvolvimento e listagem de atividades para buscar organizar diferentes atividades para as crianças. Independentemente da forma de planejar, é fundamental o cuidado com o contexto e com as necessidades das crianças, a fim de superar uma organização autocêntrica, fundamentada no preenchimento do tempo como destaca Ostetto (2011). Segundo a autora, muitas vezes “o professor busca, então, organizar vários tipos de atividades para realizar durante cada dia da semana" (OSTETTO, 2011, p. 2). 
Para tanto, existem diferentes tipos de planejamentos utilizados na Educação Infantil. Um dos modos de planejar nesse segmento é por projetos, os quais devem trazer componentes que as crianças identifiquem e possam propor conhecimentos para o seu dia a dia. Para Barbosa et al. (2011, p.46), “um projeto é a procura da solução de um ato problemático levado à realização completa em um ambiente real, tendo um compromisso com a transformação da realidade”.

Os planejamentos baseados em datas comemorativas se baseiam no calendário. Neles, professoras buscam organizar atividades referentes a feriados nacionais e datas supostamente importantes para o conhecimento da criança. Podemos citar, por exemplo, as atividades voltadas para o Carnaval, o Dia do índio, a Páscoa, o Dias das Mães e o Dia dos Pais, etc. Ostetto (2011) destaca que este formato de planejamento vem da ideia de heróis e vencedores, de maneira ideológica e política, pois algumas datas são comemoradas e outras não. Conforme a autora, é importante destacar que muitas atividades são apenas elaboradas para executar cronogramas, sem ter realmente significado para a criança.

O tema do planejamento por datas comemorativas também é abordado por Maia (2011), que apresenta e discute os aspectos históricos dessa forma de planejar:

Datas são conservadas e valorizadas, muitas vezes, em nome de uma tradição que justifica sua manutenção. Tradição que constitui e mantém a identidade de uma sociedade ou grupo que se reconhece nas histórias, nas ideias e sentimentos perpetuados (MAIA, 2017, p. 3).

A autora ainda ressalta que precisamos refletir sobre o porquê de algumas datas e não outras, enfatizando a relação com o contexto, com a comunidade, com a diversidade.

O planejamento por temas de interesse é estruturado na proposta de Ovide Decroly, que valorizava as escolhas da criança e definia estes interesses em cinco grandes áreas: a criança e a família; a criança e a escola; a criança e o mundo animal; a criança e o mundo vegetal; a criança e o mundo geográfico, a criança e o universo. Estas grandes áreas poderiam substituir os planos de estudo construídos com base em disciplinas.

Em Paulo Freire (1984), encontramos, anos mais tarde, a abordagem dos temas geradores, diante de proposta dialógica de estudo e compreensão da realidade. Ostetto (2011, p. 185) destaca que "os temas escolhidos pelo professor, sugeridos pelas crianças ou sugeridos de situações particulares e significativas vivenciadas pelo grupo, indicam o trabalho a ser desenvolvido".

É possível também organizar o planejamento com base nos aspectos do desenvolvimento, o que tem origem nos estudos da psicologia, com ênfase a partir da década de 70. Os escritos de Piaget e Vygotsky, dentre outros autores, tratam das fases de desenvolvimento infantil, como apontam Eidt e Ferracioli (2007, p. 109). 
No planejamento pelos aspectos do desenvolvimento, o professor precisa compreender como a criança se desenvolve e aprende, respeitando sua faixa etária. De acordo com Ostetto (2011), é preciso cuidado, pois muitos professores, ao utilizarem esse planejamento baseado em aspectos gerais da criança, deixam de tomar cuidado com as características individuais. A autora ressalta que se trata de uma maneira interessante ao organizar as propostas com as crianças, o que, por sua vez, exige profundo conhecimento e discernimento para se planejar o que é geral de cada etapa, sem se perder de vista o específico de cada criança, de seu tempo e de sua realidade.

Outra forma identificada é a organização da rotina com uma listagem de atividades. Essa maneira de planejar é entendida por Ostetto (2011) como rudimentar, pois apenas se preocupa em ocupar o tempo de trabalho realizando diferentes atividades a cada dia da semana. A listagem de atividades quase não pode ser classificada como planejamento, dado que a intencionalidade do educador não está marcadamente definida considerando-se princípios educativos, muito embora exista, por trás dessa prática, uma concepção, mesmo que implícita, de criança e educação infantil. Poderíamos assinalar que a criança que aparece é uma criança passiva, sem particularidades ou necessidades específicas, que espera pelo atendimento do adulto, sem nada a dizer ou expressar (OSTETTO, 2011).

Dentre as possibilidades e formas do planejar, o que ecoa na prática? Seguimos apresentando algumas considerações tecidas com base no que nos dizem as professoras da Educação Infantil.

\section{As professoras, seus saberes e fazeres: planejamento no cotidiano da educação infantil}

Para compreender as formas e os usos do planejamento no cotidiano da Educação Infantil, optamos por indagar as professoras acerca de seus saberes e seus fazeres sobre o planejar, utilizando como recurso o questionário ${ }^{3}$. Amparadas na análise de conteúdo (BARDIN, 1977), organizamos os dados em categorias, que visam fornecer, por meio da condensação, uma forma simplificada da representação dos dados brutos.

As categorias deste estudo foram definidas com base nas especificidades das questões do instrumento de coleta de dados (questionário), visto que as questões 1, 2 e 3 tratam da concepção do planejamento e as questões 4 e 5 abordaram a prática de planejar.

\footnotetext{
${ }^{3}$ Instrumento de geração de dados composto de 5 perguntas abertas, distribuído para 10 professoras, com a devolutiva de 3 professoras da rede municipal e 3 professoras de instituições privadas.
} 
Tabela 1 - As categorias de análise

\begin{tabular}{c|c} 
Categoria 1 & Categoria 2 \\
Concepção de planejamento & Prática de planejar \\
\hline Entendimento de planejamento & Maneiras de planejar \\
\hline O planejar na Educação Infantil & Relação planejamento-PPP \\
\hline Características de um bom planejamento & \\
\hline
\end{tabular}

Fonte: Organizado pelas autoras.

$\mathrm{Na}$ categoria Concepção de Planejamento, tratamos do âmbito conceitual com base nas concepções de planejamento obtidas das respondentes, e, na categoria Práticas de Planejar, abordamos os aspectos relacionados à prática de planejar expressa pelas respondentes, ambas amparadas no referencial teórico que compõe este estudo.

\section{Os saberes sobre o planejar na Educação Infantil}

$\mathrm{O}$ ato de planejar é colocado como uma atividade intencional para a qual se projetam fins e deve ser ideologicamente comprometido; implica escolhas e escuta, é uma atividade e um meio que subsidiam o encaminhamento de ações e a obtenção de resultados desejados.

Quando buscamos identificar qual o entendimento das professoras sobre o planejar na Educação Infantil, verificamos que elas ainda não têm um conhecimento claro e fundamentado sobre este assunto. Entre as respostas obtidas nos questionários, as professoras nos dizem que o planejar é um objetivo a se alcançar, fundamental, é preciso para a articulação dos trabalhos, serve para promover o desenvolvimento e é necessário para se ter um planejamento adequado.

Tabela 2 - O planejar na Educação Infantil

\begin{tabular}{c|c|}
\hline Variantes & Quantidade de ocorrências \\
\hline Objetivo a alcançar & 1 \\
\hline Fundamental & 3 \\
\hline Articulação dos trabalhos & 1 \\
\hline Promover desenvolvimento & 2 \\
\hline Necessário & 2 \\
\hline
\end{tabular}

Fonte: Dados da pesquisa.

Nas respostas obtidas, verificamos palavras soltas, sem uma fundamentação que nos indique uma convicção a respeito da importância de se planejar a prática pedagógica com crianças.

Ao analisarmos as respostas das professoras, observamos também que elas não apresentam uma compreensão das especificidades da Educação Infantil. Neste sentido, recorremos aos escritos de Rau (2011), que menciona o quanto é importante considerar a criança como sujeito de direitos, que ela possa brincar, conhecer, questionar, enfim, construir seus saberes. 
Ainda segundo as contribuições de Guerra e Asseker (2011), as autoras destacam que as ações que norteiam o trabalho do professor devem ser vistas e pensadas de maneira que contemplem as crianças, suas particularidades e seu processo de desenvolvimento, atendendo às necessidades de sua faixa etária, bem como a maneira de agir e pensar as coisas.

Retomamos os escritos de Redin (2014), para quem as crianças pequenas necessitam de uma dinâmica envolvente e sedutora, que exige dos profissionais um planejamento flexível, com propostas de atividades que possam ser modificadas quando necessário. Assim, temos as respostas das professoras referentes ao planejamento:

\footnotetext{
Em qualquer nível de ensino, se faz necessário o planejamento. $\mathrm{Na}$ Educação Infantil não é diferente.

(Professora A)

O planejamento é fundamental em qualquer nível de ensino e na Educação Infantil não seria diferente, pois exige um olhar atento às necessidades dos alunos.

(Professora D)
}

É possível identificar certa fragilidade no que se refere ao entendimento das professoras sobre o conceito e a importância do planejamento para o processo de ensino e aprendizagem da criança pequena. As respostas indicam uma concordância com a importância do planejamento, mas não apresentam elementos específicos quanto à educação de crianças pequenas, à organização e ao cotidiano da Educação Infantil, que se estrutura geralmente em período integral. Isso pode ocorrer possivelmente em função de que, muitas vezes, as profissionais terminam o ensino superior sem um preparo mais consistente de seu papel profissional.

Gomes (2009, apud ARAUJO; SOUZA, 2013, p. 3) contribui ao afirmar que:

\begin{abstract}
Pensar a educação de crianças pequenas envolve não só considerar a travessia dos profissionais de creches para a área da educação e o processo de profissionalização docente levado a efeito pelas instituições formadoras sem descaracterizar as histórias, as experiências até então existente de educação e cuidados, mas também buscar a superação dos assistencialismos e objetivar a garantia dos direitos da infância, assim como dos educadores.
\end{abstract}

Neste sentido, apontamos como necessário que os espaços de formação de professores permitam o acesso a diferentes conhecimentos sobre o planejamento, sobre as etapas da educação básica, sobre as crianças e seus contextos, sobre a escuta e a partilha de conhecimentos, pois, amparadas nos escritos de Ostetto (2000) e Maia (2011), entendemos que, para uma proposta coerente de planejamento, é preciso ir além de um instrumento de organização, o qual deve estar também vinculado ao real, à vida em seu movimento e na busca de acompanhar as crianças e o seu processo de construção de conhecimento. 
Reiteramos a importância do planejar para ampliar as possibilidades, para indagar, oferecer o novo, criar repertórios, experimentar, sem amarrar e predeterminar tempos e formas.

Ressaltamos como fundamental que o professor se perceba como protagonista, que esteja atento às necessidades da criança, compreendendo a importância de suas singularidades, buscando subsídios que possam alicerçar seu trabalho frente às exigências que a prática pedagógica necessita, e para tal é fundamental o fortalecimento da formação tanto no âmbito inicial quanto na formação continuada.

Indagamos os professores, então, sobre o que é um bom planejamento e tecemos algumas considerações.

\section{$7 \mathrm{O}$ que é um bom planejamento? Vozes e saberes}

Conforme abordamos ao longo do estudo, entendemos que o planejamento educacional é um instrumento orientador de todo o processo educativo, pois constitui e determina as grandes necessidades, indica as prioridades básicas, ordena e determina todos os recursos e meios necessários para atingir as grandes finalidades.

Com relação à questão que indagou as professoras quanto aos aspectos que seriam necessários para um bom planejamento, elas relatam que esse planejamento deve ser flexível, conter data, faixa etária, objetivos, metodologias e recursos que devem contemplar o aluno em sua totalidade, nos sentidos cognitivos, motor e social, bem como respeitar a realidade dele, desenvolvendo sua criatividade.

Tabela 3 - Características de um bom planejamento

\begin{tabular}{c|c|}
\hline Variantes & Quantidade de ocorrências \\
\hline Flexível & 2 \\
\hline Conter data & 2 \\
\hline Faixa etária & 2 \\
\hline Objetivos & 2 \\
\hline Metodologias & 3 \\
\hline Contemplar o aluno como um todo & 1 \\
\hline Respeitar a realidade do aluno & 1 \\
\hline
\end{tabular}

Fonte: Dados da pesquisa.

Portanto, o bom planejamento necessita de variadas características justamente para que um bom plano de ensino seja desenvolvido. Para Nervi (1967), citado por Gama e Figueiredo (2009, p. 7), o planejamento é flexível quando: 
[...] permite a inserção sobre a marcha de temas ocasionais, subtemas não previstos e questões que enriqueçam os conteúdos por desenvolver, bem como permitir alteração, de acordo com as necessidades ou interesses dos alunos.

Podemos então entender que, quando as professoras mencionam que o planejamento deve ser flexível, sabem que, apesar de ter algo já programado, o planejamento, conforme a necessidade do momento, deve ser maleável e passível de mudanças, mas que não deixe de acompanhar o desenvolvimento das crianças.

Quanto aos aspectos de apresentação do planejamento além dos conteúdos, deve ser funcional, promovendo condições e integrações dos conhecimentos para a aprendizagem. Encontramos na didática pontos específicos para um bom planejamento, como coerência e unidade, continuidade e sequência, objetividade e funcionalidade, precisão e clareza, o que auxilia na organização de dados e etapas a serem trabalhadas.

Gama e Figueiredo (2009, p. 7) ressaltam que o trabalho realizado pelo professor encaixa uma sequência, uma linha de raciocínio, em que se tenha a real consciência do que se ensina e quais os objetivos que se espera atingir, para que nada fique disperso ao acaso. As respostas das professoras pesquisadas em relação ao bom planejamento trazem os seguintes dados:

O planejamento deve conter a data, a faixa etária, os objetivos a serem alcançados, o conteúdo a ser elaborado de forma detalhada, os recursos que serão utilizados.

(Professora A)

Todas as estruturas desde a proposta de conteúdos, rotina, recursos, mobilização, desenvolvimento do que se pretende ensinar, qual a metodologia a ser aplicada, atividades de desenvolvimento psicomotor, atividades de fixação, música e movimento, histórias das mais diversas fontes, recreação dirigida e livre, e, se necessário, conforme a idade, atividades para casa que envolvam e mobilizem os seus responsáveis.

(Professora E)

Percebemos que as professoras citam diferentes itens para dizer o que um bom planejamento deve conter. As professoras mencionadas (A e) colocam o conteúdo proposto, pois é preciso saber o que será desenvolvido com as crianças. Carlini (2004, p. 127) aponta que "embora os conteúdos de ensino constituam o cerne da relação pedagógica e o aspecto essencial da aula, precisam ser organizados".

Outros fatores sobre os quais as professoras responderam foram atividades de fixação, música, movimento, histórias diversas, recreação. O que se pôde observar nestas respostas é que as professoras buscam procedimentos de ensino que ajudem a ensinar, envolver as crianças e estimulá-las. Segundo Scarpato (2004, p. 21), “Os procedimentos de ensino são um ato de escolha, 
na prática docente, a fim de melhor propiciar a aprendizagem integral dos educandos, o que significa causar-lhes transformação".

Luckesi (1992) afirma que o planejamento é um conjunto de ações preparadas projetando um determinado objetivo. Nesse sentido, "é um conjunto de ações coordenadas visando atingir os resultados previstos de forma mais eficiente e econômica" (LUCKESI, 1992, p. 121). Logo, o planejamento deve ser visto como uma ação transformadora que envolve métodos, concepções e organização pedagógica, fundamentais a toda constituição do fazer educacional.

\title{
8 Entre as práticas, as maneiras de planejar
}

O professor da Educação Infantil precisa planejar suas ações tendo em vista a faixa etária e as especificidades a que se destinam, organizando suas atividades de forma lúdica, criativa e flexível. Segundo Ostetto (2000, p.1),

\begin{abstract}
[...] o planejamento educativo deve ser assumido no cotidiano como um processo de reflexão, pois, mais do que ser um papel preenchido, é atitude, e envolve todas as ações e situações do educador no cotidiano do seu trabalho pedagógico. Planejar é essa atitude de traçar, projetar, programar, elaborar um roteiro para empreender uma viagem de conhecimento, de interação, de experiências múltiplas e significativas para com o grupo de crianças. Planejamento pedagógico é atitude crítica do educador diante de seu trabalho docente. Por isso não é uma forma! Ao contrário, é flexível e, como tal, permite ao educador repensar, revisando, buscando novos significados para sua prática pedagógica.
\end{abstract}

Pensar, conhecer, saber da criança, saber o que a criança precisa, entender enquanto profissional a importância de sua prática, superar a reprodução inconsciente. A organização escolar deve ser trabalhada no sentido de melhorar e implementar as atividades na escola. Consideramos necessário que a organização educacional deixe de fragmentar o conhecimento e produza um modelo organizacional mais eficiente, prático e envolvente, e na Educação Infantil, além dessa organização, é preciso ter clara a ideia de cuidar associada a uma formação continuada e com um trabalho pedagógico organizado e sistematizado.

O planejamento se torna essencial enquanto se busca o desenvolvimento do aluno e seu processo de ensino-aprendizado. O planejar é a possibilidade de darmos uma direção às ações que se pretende realizar. Nesse sentido, podemos considerar que existem variadas formas de se realizar um bom planejamento, com vistas a atender às necessidades que o aluno apresenta.

Ao questionarmos as professoras participantes da pesquisa sobre as maneiras de se planejar, as respostas, em sua maioria, ressaltam que elas planejam por projetos, segundo a faixa etária, que pode ser também planejamento semanal e cooperativo. 
Tabela 4 - Maneiras de planejar

\begin{tabular}{c|c|}
\hline Variantes & Quantidade de ocorrências \\
\hline Projetos & 3 \\
\hline Datas comemorativas & 1 \\
\hline Semanal e cooperativo & 2 \\
\hline
\end{tabular}

Fonte: Dados da pesquisa.

Diante destas respostas, voltamos aos escritos de Souto-Maior (1997), quando comenta que os projetos de trabalho podem nascer de qualquer situação ou acontecimento, o professor precisa apenas proporcionar meios para favorecer a construção desses conhecimentos, considerando, dessa forma, as especificidades das crianças, sua faixa etária e, sobretudo, fazendo uma leitura do grupo na totalidade.

Quanto ao emprego do termo cooperativo, justifica-se a partir dos pressupostos pedagógicos de Freinet ${ }^{4}$ (1989), no que se refere às crianças, sua infância e seu desenvolvimento. Segundo esse princípio, a metodologia é aplicada de forma inovadora, intencional, com atividades que incluem textos coletivos, painéis, tudo partindo sempre do interesse do aluno ou de um coletivo, fazendo com que a criança participe ativamente desse processo.

Guerra e Asseker (2011) vêm contribuir ressaltando a necessidade de o professor ter um olhar atento, no sentido de buscar atividades que auxiliem o aluno na construção de seus conhecimentos. Diante disso, verifica-se que a escolha da forma como será trabalhado com o aluno deve integrar seu processo de desenvolvimento. No que diz respeito às abordagens do planejamento, Klosouski e Reali (2008) ressaltam pontos importantes, como:

1 - Considerar a forma de aprender de cada um, considerando hipóteses, progressos e perguntas a respeito dos temas;

2 - Considerar que é importante e significativo para aquela turma. Ter claro onde se quer chegar, que recortes devem ser feitos para escolher temáticas e que atividades deverão ser implementadas. (KLOSOUSKI; REALI, 2008).

Assim, faz-se necessário que o professor contemple, em seu planejamento, aspectos que tragam significado para a criança, com respeito à cultura, ao conhecimento prévio e às potencialidades das crianças, propostas que despertem seu interesse, instiguem a reflexão, ora desenvolvidas para as particularidades, ora que contemplem o coletivo, pelos temas de interesses em comum.

Quanto ao planejamento relacionado aos projetos, como já mencionado, é um dos mais trabalhados na Educação Infantil, sendo preciso observar as crianças e seus interesses e desenvolver possibilidades de trabalho próprio, mas que respeite o que as crianças buscam. Ostetto

${ }^{4}$ Célestin Freinet: O educador francês desenvolveu atividades hoje comuns, como as aulas-passeio e o jornal de classe, e criou um projeto de escola moderna e democrática. 
nos instiga a pensar as crianças ao abordar a importância de "estar na relação com as crianças (e não com só alunos!), mergulhar na aventura em busca do desconhecido, construir a identidade de grupo com as crianças" (OSTETTO, 2012, p. 6).

Entendemos que, quando se trabalha com projetos, busca-se observar a criança e seu conhecimento, seu espaço e cultura, podendo-se sempre reavaliar o trabalho pedagógico para constituir da melhor forma o processo educativo.

\section{Das reflexões às possibilidades: algumas considerações}

Estar em contato com as diversas reflexões propiciadas ao longo da formação inicial e, em especial, no espaço do Estágio de Docência, nos instigou a pensar sobre o planejamento na Educação Infantil. As práticas vistas e vividas nos mobilizaram a pensar como elas surgem, qual é o elemento disparador e que caminhos são pensados para cada proposta, elementos que fazem parte do planejamento.

Dessa maneira, este trabalho teve como objetivo investigar o entendimento das professoras da Educação Infantil sobre suas concepções de planejamento. Para tanto, com base em nossos estudos, pesquisas e questionário aplicado para as professoras, temos o propósito de ressaltar a importância do planejamento escolar para todo o processo de ensino-aprendizagem referente à Educação Infantil. A grande surpresa foi que, num primeiro momento, foram poucos os autores encontrados que abordam a temática do planejamento mediante as particularidades da Educação Infantil.

Nos primeiros passos da pesquisa, pudemos ter como amparo o referencial teórico delimitado para o estudo. $\mathrm{O}$ aprofundamento nos estudos quanto ao planejamento nos permitiu outros olhares, caminhamos por conceitos ora da didática, ora dos textos específicos da Educação Infantil, a fim de dialogarmos sobre o planejamento. A partir das respostas obtidas por meio do questionário, pudemos apontar que os professores reconhecem a importância da construção do planejamento, embora ainda existam fragilidades e equívocos em relação ao que se entende e espera por planejamento na Educação Infantil.

Tanto os teóricos quanto as normatizações da Educação Infantil remetem à necessidade de que o professor que trabalha com essa faixa etária tenha clareza em suas ações e que sua intencionalidade vise contemplar a criança em todos os seus aspectos. No entanto, as respostas dos questionários nos trazem uma interpretação superficial para essas questões.

Consideramos que as professoras $\square$ talvez subordinadas pelas rotinas e pela naturalização dos "modelos de dar aulas" transpostos para a Educação Infantil $\square$ não vivenciam o planejamento 
como uma ferramenta para a reflexão da prática, para aprimorar os saberes das crianças, suas culturas, seus cotidianos e suas comunidades.

Percebemos ser necessário para nós, enquanto professoras, verificar a necessidade de valorização do planejamento escolar, com tomada de decisões e de resgate dos princípios que embasam a prática pedagógica. É imprescindível que professores e coordenação pedagógica compreendam a importância do planejamento para a criança e com a criança, olhando atentamente para todo o trabalho realizado na escola/instituição. Sendo assim, no espaço da instituição educativa deve se efetivar uma ação qualificada, voltada para a criança como sujeito de direitos (direito à educação, cultura, lazer), que necessita de articulação com a prática cotidiana e no seu fazer educativo.

Ao iniciarmos este estudo, apontamos como questão norteadora: qual a importância do planejamento escolar na Educação Infantil? Ao traçarmos algumas considerações, destacamos que o planejamento é importante para qualquer etapa educativa. Entendemos que é no ato de planejar que o professor irá refletir sobre como pode conduzir seu trabalho com as crianças e, dessa maneira, o planejamento não pode ser considerado somente como um documento que deve ser preenchido para o cumprimento de normas.

Ou seja, deve ser visto como algo prazeroso, de modo que sua construção, vivência e reflexão tragam significados construtivos para o processo de ensino-aprendizagem das crianças e para a constituição do professor, que cotidianamente pergunta, reflete, refaz e segue se encantando com as possibilidades de estar com crianças. Não se tem uma fórmula, um modelo único, pois o planejamento precisa ser construído no diálogo e revisitado segundo as necessidades de cada professor e de cada turma-grupo.

\section{Referências}

ARAUJO, E. A. de; SOUZA, T. C. de. Pensar reflexivo: base para a formação docente no desenvolvimento da prática na Educação Infantil. In: CONGRESSO NACIONAL DE EDUCAÇÃO - EDUCERE, 11., 2013, Curitiba: PUC/PR, 2013. Disponível em: https://blu181.mail.live.com/mail/ViewOfficePreview.aspx?messageid=mgqn6jLKWU5RGa0g AhWtc_AA2\&folderid $=$ flinbox\&attindex $=2 \& c p=-1 \&$ attdepth $=2 \& \mathrm{n}=73280807$. Acesso em: 28 set. 2015.

BARBOSA, M. C. S. Práticas cotidianas na Educação Infantil. Bases para a reflexão sobre as Orientações Curriculares. Brasília: Secretaria de Educação Básica; UFRS, 2009.

BARBOSA, M. C. S. Trabalhando com projetos. In: Cadernos Educação Básica. Porto Alegre: Mediação, 2011. 
BARDIN, L. Análise de conteúdo. Lisboa: Edições 70, 1977.

BRASIL. Ministério da Educação/Secretaria da Educação Básica. Diretrizes Curriculares Nacionais Para a Educação Infantil.- Brasília: MEC/SEB, 2009.

BRASIL. Ministério de Educação e Cultura. LDB - Lei no 9.394/96, de 20 de dezembro de 1996. Estabelece as diretrizes e bases da Educação Nacional. Diário Oficial da União Brasília, 23 dez. 1996. Brasília: MEC, 1996. Disponível em:

http://www.planalto.gov.br/ccivil_03/leis/19394.htm. Acesso em: 3 jun. 2020.

BRASIL. Ministério da Educação. Diretrizes Curriculares Nacionais de Educação Infantil. Resolução CNE/CEB 20/2009. Diário Oficial da União, Brasília, 18 de dezembro de 2009, Seção 1, p. 18.

CARLINI, A. L. E agora: preparar a aula.... In: CARLINI, Luiza (org.). Os procedimentos de ensino fažem a aula acontecer. São Paulo: Avercamp, 2004.

CRAIDY, C. M.; KAERCHER, G. E. P. da S. (org.). Educação Infantil: Pra que te quero? Porto Alegre: Artmed, 2001.

DEWEY, J. O pensador que pôs a prática em foco. Revista Especial Grandes Pensadores, 2008. Disponível em: http://revistaescola.abril.com.br/formacao/john-dewey-428136.shtml. Acesso em: 17 nov. 2015.

EIDT, N. M.; FERRACIOLI, M. C. O ensino escolar e o desenvolvimento da atenção e da vontade de: superando a concepção organicista do Transtorno de déficit de atenção e hiperatividade (TDAH). In: ARCE, A.; MARTINS, L. M. (Orgs.). Quem tem medo de ensinar na Educação Infantil? Em defesa do ato de ensinar. Campinas: Alínea, 2007.

FREIRE, P. Pedagogia do oprimido. Rio de Janeiro: Paz e Terra, 1984.

GAMA, A. S.; FIGUEIREDO, S. A. O planejamento no contexto escolar. 2009. Disponível em: http://www.discursividade.cepad.net.br/EDICOES/04/Arquivos04/05.pdf. Acesso em: 2 jun. 2015.

GUERRA, E. R.; ASSEKER, A. Concepscões de Planejamento por Professores da educação infantil de uma Creche do Recife. 2011. Trabalho de Conclusão de Curso (Graduação em Pedagogia) - Universidade Federal de Pernambuco, Recife, 2011.

JUNQUEIRA FILHO, G. de A. Linguagens geradoras: seleção e articulação de conteúdos em Educação Infantil. Porto Alegre: Mediação, 2005.

KLOSOUSKI, S.S.; REALI, K. M. Planejamento de ensino como ferramenta básica do processo ensino-aprendizagem. Revista Eletrônica Lato Sensu, v. 9, n. 1, 2008.

LUCKESI, C. C. Filosofia da educação. São Paulo: Cortez, 1992. 
MAIA, M. N. V. G. Educação infantil: com quantas datas se faz um currículo? Dissertação (Mestrado em Educação) - Pontifícia Universidade Católica do Rio de Janeiro, Departamento de Educação, Rio de Janeiro, 2011. Disponível em: https://doi.org/10.17771/PUCRio.acad.21707. Acesso em: 12 maio 2021.

OSTETTO, L. E. Planejamento na Educaşão Infantil... mais que a atividade. A criança em foco. Campinas: Papirus, 2000.

OSTETTTO, L. E. (Org.). Encontros e encantamentos na educação infantil. Campinas: Papirus, 2012.

RAU, M. C. T. D. Educação Infantil: práticas pedagógicas de ensino e aprendizagem. 1. ed. Curitiba: IBPEX, 2011. v. 3. 318 p.

REDIN, M. M. et al. Planejamento, práticas e projetos pedagógicos na educação infantil. Porto Alegre: Mediação, 2014.

SACRISTÁN, J.G. Poderes instáveis em educação. Porto Alegre: Artmed Sul, 1999.

SCARPATO, M. (org.). Os procedimentos de ensino fazem a aula acontecer. São Paulo: Avercamp, 2004.

SOUTO-MAIOR, S. D. Relato de uma aventura: mapas, diários de bordo e tesouros, organizando e transformando o trabalho do educador infantil. Florianópolis: UFSC, 1997. (Relatório de estágio - Curso de Pedagogia). 